\title{
Marc Lapprand, V comme Vian
}

\section{Sara Arena}

\section{(2) OpenEdition}

\section{Journals}

\section{Edizione digitale}

URL: http://journals.openedition.org/studifrancesi/9332

DOI: 10.4000/studifrancesi.9332

ISSN: 2421-5856

\section{Editore}

Rosenberg \& Sellier

\section{Edizione cartacea}

Data di pubblicazione: 1 juin 2008

Paginazione: 222

ISSN: 0039-2944

\section{Notizia bibliografica digitale}

Sara Arena, «Marc Lapprand, V comme Vian», Studi Francesi [Online], 154 (LII | I) | 2008, online dal 30 novembre 2015, consultato il 09 janvier 2021. URL: http://journals.openedition.org/studifrancesi/9332 ; DOI: https://doi.org/10.4000/studifrancesi.9332

Questo documento è stato generato automaticamente il 9 janvier 2021.

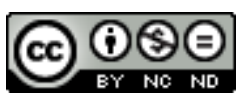

Studi Francesi è distribuita con Licenza Creative Commons Attribuzione - Non commerciale - Non opere derivate 4.0 Internazionale. 


\title{
Marc Lapprand, V comme Vian
}

\author{
Sara Arena
}

\section{NOTIZIA}

MARC LAPPRAND, V comme Vian, Lévis (Québec), Les Presses de l'Université Laval, 2006, pp. 255.

1 In consonanza con un certo gusto dello stesso Boris Vian per le classificazioni e per le costruzioni sistematiche, e in armonia con la sua spiccata propensione al gioco e a un trattamento ludico del linguaggio e delle tecniche compositive (cfr. «Introduction», p. 15), il libro di Marc Lapprand considera l'opera di Vian attraverso il filtro di ventisei nozioni, organizzate in ordine alfabetico in un immaginario, e personale, abbecedario di parole chiave.

Dalla A di «Afnor» - sigla dell'Association française de normalisation dove Vian ebbe il suo primo impiego - alla Z di «Zénobie» - personaggio di Les Bâtisseurs d'empire - l'elenco accosta nomi di luoghi e persone (ma anche oggetti, come «Brasier», l'automobile acquistata da Vian nel 1950) desunti dalla biografia dell'autore a termini relativi allo stile e alla scrittura («Formaliste», «Incipit», «Humour»), parole e nomi inerenti alla sua collocazione nel panorama culturale del tempo («Surréalisme», ma anche «Ellington» e «Queneau») a temi dell'opera («Jaune», «Nénuphar», il numero «Onze»), e traccia per ognuna delle entrées della lista un commento che propone, oltre alla sintesi delle acquisizioni della critica, suggestioni, associazioni e proposte originali. Le voci, sempre precedute da una citazione a tema tratta da testi di Vian, sono collegate tra loro da frequenti rimandi interni.

3 Nato sulla scia di un numero speciale della rivista «Obliques» del 1976, già organizzato come un 'abbecedario' della vita e dell'opera di Boris Vian, e del Dictionnaire Vian di Gilbert Pestureau (1985), che raccoglie in ordine alfabetico i personaggi dei suoi romanzi, il repertorio di Marc Lapprand si propone, per la sua stessa struttura, soprattutto come un valido punto di partenza per possibili approfondimenti, piste di indagine e ulteriori studi su aspetti puntuali dell'opera di Vian da parte di chi già ne 
conosca i tratti principali, o come strumento per un primissimo approccio, inconsueto e trasversale, alla sua personalità e alle particolarità della sua produzione. 